\title{
Tree Speech: An Analysis of Discourses on Permanent Reserved Forests in Malaysian Debates since 1959
}

\author{
Alia Azmi ${ }^{1^{*}}$ and Rhosanna Jenkins ${ }^{2}$ \\ 1 Centre of Environmental Health and Safety, Faculty of Health Science, Universiti Teknologi MARA, \\ Puncak Alam, Selangor, MY \\ 2 Tyndall Centre for Climate Change Research, University of East Anglia, Norwich Research Park, Norwich, \\ NR4 7TJ, UK \\ * Correspondence author: aliaazmi@uitm.edu.my; Tel.: +603 32584576
}

\begin{abstract}
As a country that once relied heavily on the forestry industry, Malaysia is slowly trying to change their economic dependence to a more sustainable resource, however, the continued reliance on forest resources is creating a conflict between protection as well as development of the forest reserves. To better understand the conflict that exists within the debates among the political elites in Malaysia, this paper examines the speeches on permanent reserved forests by decision makers in the Malaysian Parliamentary debates. These parliamentary debates $(n=229)$ were analysed using content analysis where three major themes in PRFs were identified: (1) industry and economic development; (2) environmental protection, conservation and impact; and (3) social development and community rights. Results show that economic concerns related to agriculture, timber and development dominated the parliamentary debates throughout the early discussions and the topic of PRF has been framed as primarily an economic issue by the political elites throughout the period of analysis. While there have been environmental issues discussed frequently in the debates, little change has occurred in the discussions on PRFs, which means the fundamental policy underpinning the management of these forests has not changed since colonial times. Peaks in the discussion of permanent reserved forests are associated with key legislations and events within Malaysia. This analysis indicates that the governance of PRF is largely unchanged, and while the new government indicated change could occur, the fact that they fell within two years of election does not lend to a positive note. The analysis has implications for future governance of forestry in Malaysia, which is decidedly embedded within the principle of resource use, inherited from the British era. If forests are to be protected, the fundamental principle of resource use has to be reconstructed entirely.
\end{abstract}

Keywords: forest; permanent reserved forest; parliamentary debates; policy; conservation; economic resource

\section{Introduction}

With the majority of its nations currently in the process of development and industrialization, Southeast Asia is notorious for tropical deforestation (Zeng et al., 2018). Countries like Cambodia, for instance, are gaining grounds on rural development (Riggs et al., 2020), while others, like Indonesia and Malaysia, are in the process of expansion or intensification of palm oil (Gatti et al., 2019). All of these developments and gains not only contribute to deforestation, but also to land degradation. Deforestation and land degradation are of particular concern due to their association with climate change. Although efforts such as reforestation and community-based conservation programs attempt to reverse the adverse effects of forest development, all of these must take into account the significant economic and environmental trade-offs. In Malaysia, the trade-offs between economic development and environmental conservation is a major challenge, one that has been plaguing the country for decades. To better understand this issue, this paper explores the ways in which forestry matters are debated in parliament by focusing on key areas of forest management, particularly permanent reserved forests (PRFs), and how it is discussed among the political elites in the country. 
Malaysia's forests are among the most complex ecosystems in the world (Jusoff and Taha, 2008). The area is part of the Sundaland global biodiversity hotspot due to its exceptional species diversity and richness (Myers, 1988) and not to mention an important reservoir for carbon, a key component in the fight to mitigate climate change (Kanniah et al., 2018). As such, the use and protection of forests is an important topic of discussion within Malaysian policy and legislation. As a developing country, Malaysia is slowly reducing dependence on natural resources, but the palm oil and forest plantation industry still contributes greatly to the country's gross domestic product (GDP). Malaysia is in a constant state of balancing economic development with environmental and social goals and commitments (Nagulendran et al., 2016). In its Vision 2020, the government of Malaysia set out aims to become a developed nation with a high-income status, and forestry resources are one of the highly valuable resources that are critical to achieving this aim.

However, Malaysia has also made global commitments to biodiversity protection. The Aichi Biodiversity targets for Malaysia include commitments to ensure forestry, agriculture and fisheries are sustainably managed and harvested by 2025 (Target 4 ) and to ensure at least $20 \%$ of terrestrial areas are conserved through a representative system of protected areas and other effective areabased conservation measures (Target 6) (Natural Resources and Environment, 2016). Not only that, Malaysia has made commitments towards mitigating climate change. During the 2015 United Nations Framework Convention on Climate Change (UNFCCC), Malaysia has committed to reduce emissions intensity of 35\% by 2030 (Varkkey, 2019). This is based on the understanding that protecting forests is not only important for conserving biodiversity, but also for climate change mitigation through storing carbon and contributing to adaptation by increasing water storage, which can reduce the risk of flooding, and reducing soil erosion. However, as of 2010, the percentage of terrestrial protected areas in Malaysia was only $13.8 \%$ of the total land area (Nagulendran et al., 2016) despite having at least $50 \%$ of land under forest cover.

\subsection{The Malaysian Context}

To better understand Malaysian forestry governance, a brief introduction into the Malaysian forestry system will first be presented. This provides important contextual understanding of the issue of PRFs. As the country's supreme law, the Federal Constitution establishes Malaysia as a constitutional monarchy with the Yang di-Pertuan Agong (Head of Government) as a ceremonial and religious (Islam) leader ("Federal Constitution," 1957). The Constitution also provided the basis for the organization of the government; 1] the bicameral legislative branch (Parliament) that consists of the House of Representatives (Dewan Rakyat) and the Senate (Dewan Negara); 2] the executive branch led by the Prime Minister and Cabinet Ministers; 3] and the judicial branch. The government structure in Malaysia is separated into three tiers with the federal government at the top, followed by the state government and finally local government, which handles matters pertaining to local authorities in each district.

\subsection{The Importance of Forests in Malaysia}

Following independence, Malaysia went through a period of rapid economic transformation, where Malaysia's GDP grew exponentially, and forests were heavily exploited for both timber and other non-timber resources such as rattan, bamboo and dammar (Ratnasingam et al., 2011). Currently, Malaysia is the second largest exporter of oil palm (36\% of the global total in 2019) and the third largest producer of rubber in the world. The responsibility over land and forestry belongs to state governments, with forestry management carried out by state forestry departments. Data from 2016 indicates that the size of the forested area in Malaysia is at 18.12 million hectares, accounting for approximately $55 \%$ of the total land mass. However, this calculation of forest cover is made based on the definition of a forest as 'land that covers an area of more than 0.5 hectare with height of trees over 5 meters and more than 10\% tree cover; or trees that are able to reach the aforementioned specified height and cover on site' (Natural Resources and Environment, 2017). In actuality, the total protected forest area, which includes national parks, wildlife sanctuaries and wildlife reserves makes up only $15 \%$ of the total forested area. 
Apart from the protected areas, the rest of Malaysia's forested land is classified as PRF, a term used for land gazetted under the National Forestry Act 1984 (NFA 1984). PRF denotes the largest type of forest in Malaysia, and is divided into four categories; 1] productive, 2] research and education, 3] recreation or 4] protection, with the idea that only productive PRF is allowed to be sustainably logged. However, it is unknown exactly how PRFs are divided into these four categories, nor is it clear as to the percentage of these different PRFs in relation to each other. Regardless, the NFA (1984) was introduced for the purpose of 'administration, management and conservation of forests and forestry development within the States of Malaysia'. Based on this Act, all areas previously designated as forest reserves under separate state enactments were automatically gazetted as PRFs so that the management of forests became uniform throughout the country. Prior to 1984 , forest reserve is the term commonly used to describe forests apart from those that are designated as national parks, wildlife sanctuaries or wildlife reserves, which are gazetted under a different Act. Meanwhile, although the term forest reserve was formally changed to PRFs, both terms are used interchangeably in Malaysia, and have come to mean the same thing. A PRF, also known as Permanent Forest Estate (PFE), is defined in the Act as 'any land constituted or deemed to have been constituted a permanent reserved forest'. The NFA 1984 remains the supreme legislative document, however, there are other various laws, enactments and legislations that have been introduced over the years. The complex nature of land and forestry planning necessitates the use of multiple provisions to guide the management of these resources.

This article presents an analysis of parliamentary debates from the House of Representatives in Malaysia on the topic of PRFs over a period of 60 years, beginning with the earliest archived debate dated 11 September 1959. As mentioned earlier, the overall aim of this study was to explore the archived debates on the topic of PRFs in Malaysia and how the topic has been framed by the political elites in the country. This paper begins with background information on decision making in Malaysia and the importance of PRFs. It then goes on to describe the document analysis which focused on the themes that emerged from the parliamentary debates. This analysis provides valuable insights into changes in the framing of the topic of PRFs over time. Additionally, this article also charts the evolution of the management of forest reserves and conservation over six decades. Since the parliament is the epicentre of the government, where arguments and debates over legislation and policies take place, parliamentary debate provides a primary source in exploring the position of the Malaysian government on forest reserve management and development.

Understanding the parliamentary discussions on PRFs and how these have changed over time could provide insight into progress towards environmental protection within Malaysia. The evolution of political attitudes and discussions on forest reserves reflects not only the process that shaped the past, but also future forestry policies in Malaysia and this could give an indication of progress towards global targets. With the United Nations declaring 2021-2030 as the 'UN Decade on Ecosystem Restoration', which has the purpose of recognising the need to massively accelerate global restoration of degraded ecosystems, this article is thus critical to understanding and mapping the future of Malaysia's forest ecosystem.

\section{Materials and Methods}

Records of parliamentary debates from the House of Representatives were the source of data for this study. These were downloaded from the Malaysian parliament website (Parlimen Malaysia, 2020). Each debate is a digitized record of the daily parliamentary session with the earliest archived debate dated 11 September, 1959. Initially, using the search option provided by the online archive, debates with the term 'forest reserve' or 'hutan simpan' were identified and collected. As stated in Section 1.2, the term forest reserve and PRFs are used interchangeably and when translated into Malay, the term 'hutan simpan' can more efficiently capture all mentions of PRFs. It is also important to note that the word search function may have erroneously excluded discussions that do explicitly mention PRFs, but this matter was considered during word search by also including the more generalized term of 'hutan' (forest) and then followed by manual omission of parliamentary debates that did not specifically refer to forest reserve. This resulted in 229 debates being collected for analysis, with the earliest debate mentioning forest reserves was on 6 December, 1962. The selected 
debates were then uploaded to the software NVivo 11 for analysis. A popular choice of software for qualitative research, NVivo has previously been used to investigate the discussion of environmental issues within various parliaments around the world (Sarrica et al., 2016; O'Neill et al., 2018).

The analysis was carried out using a qualitative content analysis that is embedded within a discourse analytical approach (Hardy, Harley \& Phillips, 2004). This means that unlike the use of discourse analysis as a constructionist methodology where it strives to uncover how reality is produced from the analysis of texts, the approach used in this paper focuses more on how the meaning itself is already fixed within the text and in itself reflects reality. Regardless, unlike the formal content analysis approach, this research does not separate meaning from context, and neither does it aim to provide a purely quantitative analysis of the texts. While this research analysed the content of the parliamentary debate and provided quantitative description (frequency) of the topics that emerged from the parliamentary debates, it in fact utilized both deductive and inductive approaches to analysis, with the codes emerging from the texts. Essentially, the speeches in which forest reserves or permanent forest reserves are mentioned were highlighted, analysed and coded into several specific topics. This process is interactive, where the researcher goes back and forth between the parliamentary debates and the codes. The coding of each reference to PRF is based on the topic in which the PRF is discussed in the debate. In most cases, these topics, such as the use of PRF to produce timber and logging activities in PRF, are explicit. However, in instances where the debates fall within multiple codes, then it will be coded again based on whichever categories the texts fall into. Apart from that, there are some instances where the references were coded only once based on the overall tone of the speech. For instance,

The Honourable XX has raised the issue of illegal logging in Tawau, of timber taken out in trucks from first class permanent Forest reserve. Since last year, apparently the timber is from the clearing of land for the XX factory project. Based on current approximation released by the Federal government, 429 hectare of forest has been logged for the development of the factory. For the information of this Honourable House, Director of Sabah Forestry Department, Datuk XX, before this claimed that logging was carried out to clear the land for building roads. But, $80 \%$ of road construction had been completed as of August 2013. Based on XX official website. Why is there still a lot of timber found in Tawau roads? What's interesting is that based on [info] from the Companies Commission of Malaysia, the majority shareholder in XX is Head of UMNO Youth....

[DR18112014.104]

The extract above discussed the issue of logging during the construction of a project, however, the tone of the speech refers to possible exploitation of the surrounding PRF by the governing political party. Therefore, the reference is coded under the topic 'corruption'.

\section{Results}

From the 229 identified parliamentary debates, 966 references of forest reserves were recorded and 37 specific topics were identified. The topics reflect the matters in which the PRFs were discussed, ranging from timber industry to management conflicts. These topics were then further grouped into five categories, three of which represent three major themes in PRF; 1 ] industry and economic development; 2] environmental protection, conservation and impact; and 3] social development and community rights. The other two categories; 1] legal issues and 2] management of PRF is not considered as a major theme as these categories do not reflect the ways in which PRF is governed or developed, and are therefore considered as minor categories rather than themes. Figure 1 shows the breakdown of the topics and categories. 


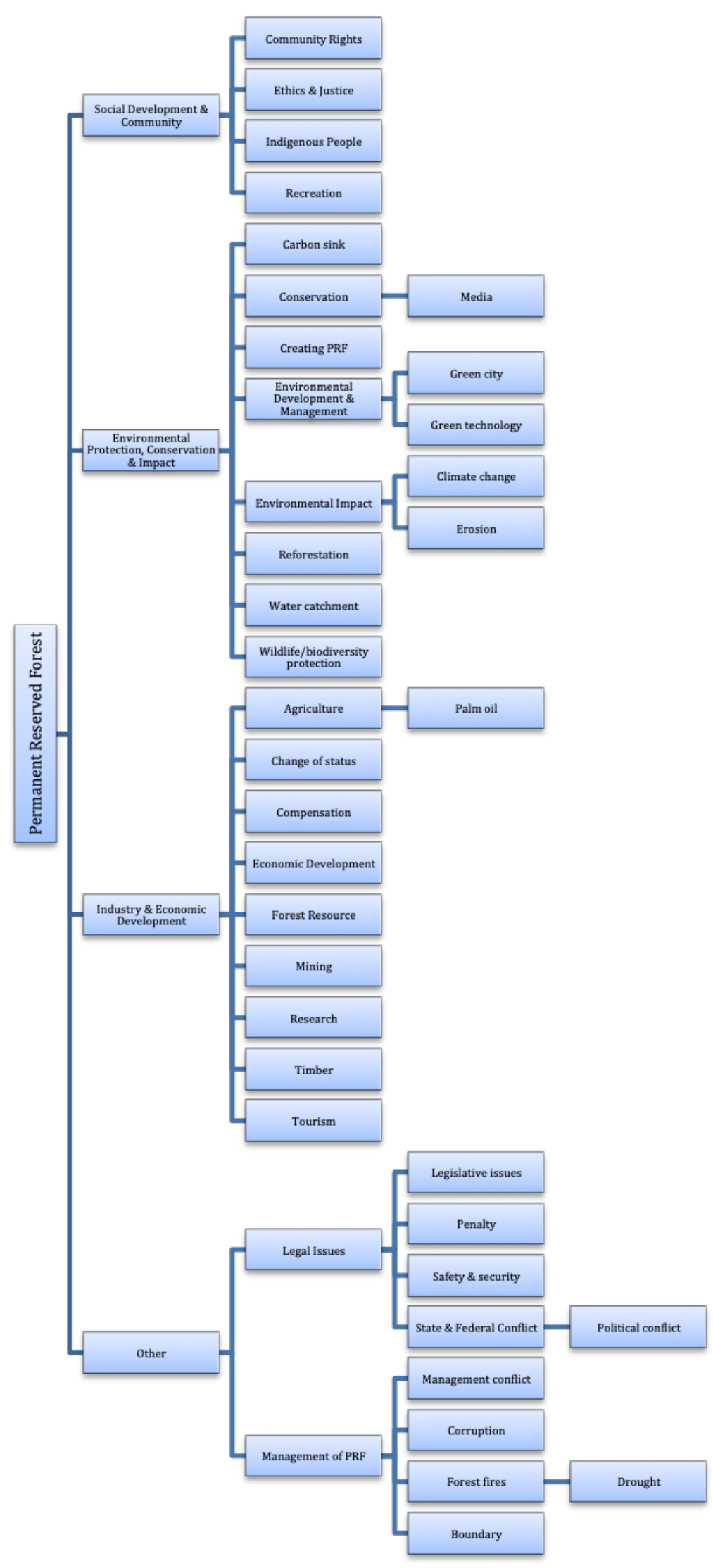

Figure 1. Diagram of topics and categories derived from analysis of parliamentary debates 
Apart from Figure 1, we also present a visualization of the topics based on the number of mentions (frequency) within the debates. This is presented in Figure 2, where the topics are organised by the year they were first discussed and the colours of the bars indicate the category that the topics were grouped into. Throughout the 60 year period, 'timber', which was first mentioned in 1968, recorded the highest reference frequency in the debates, almost double than that of the second and third highest topics, which are 'economic development' and 'environmental development and management' respectively. Most topics related to the category of 'environmental protection, conservation and impact' were not discussed until the 1970s and 1980s, although wildlife conservation was considered in earlier debates. Topics related to 'social development and community rights' were not seen in the debates until 1987 and have been infrequently discussed since. Several new topics emerged in debates after the turn of the century, such as 'compensation' where the discussion revolved around the State government requesting compensation for forest protection from the Federal government. Other topics, such as the relationship between PRF and carbon sinks, were not considered in Parliamentary debates until 2015.

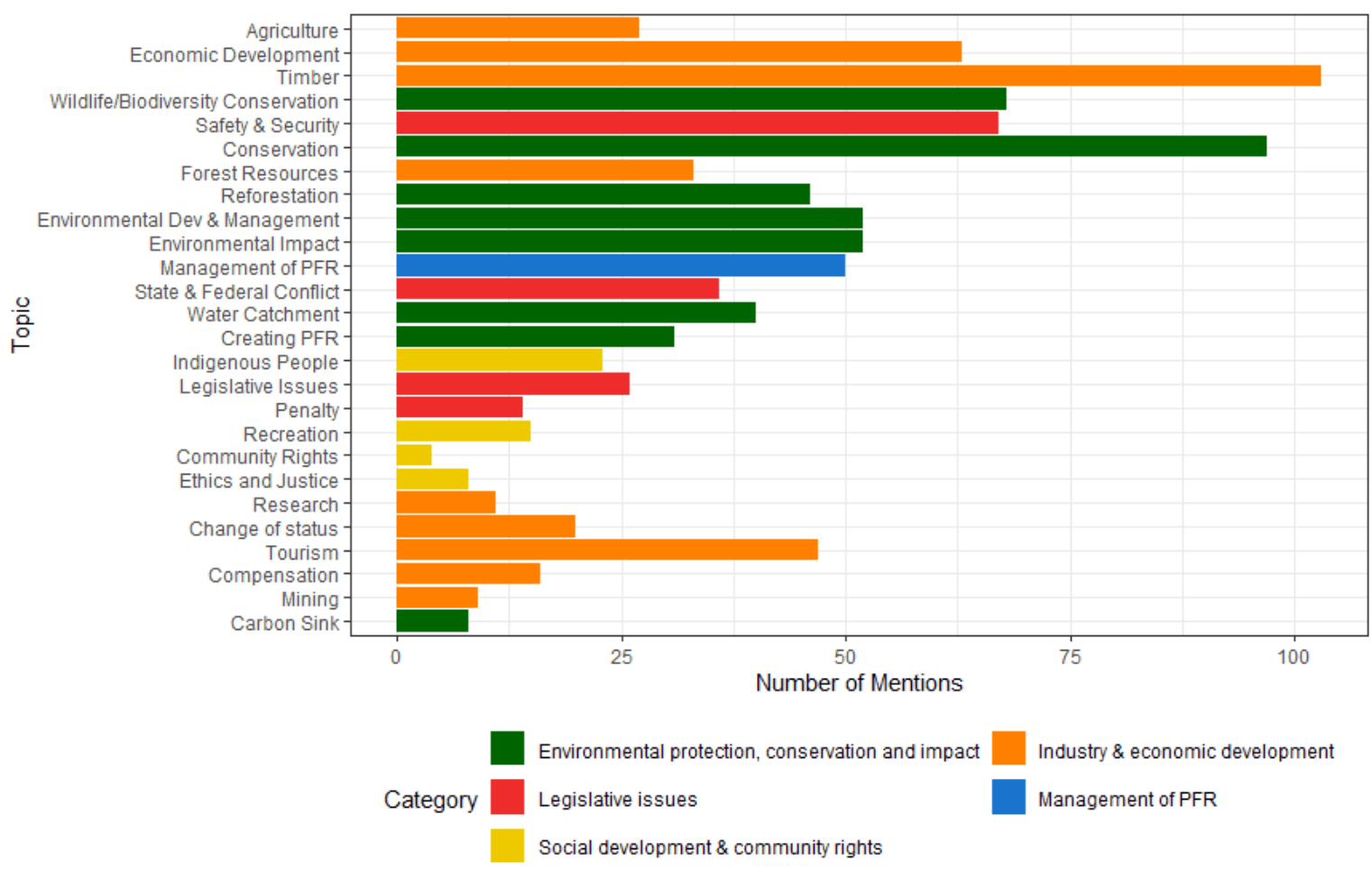

Figure 2. Frequency of reference in Hansards for the different topics identified. The topics are ordered by the date they are first mentioned, with the earliest at the top and the most recent at the bottom. The colours represent the larger category that the topics were classified into, as shown in Figure 1 (Source: NVivo)

Figure 3 shows the relative importance of the five categories in debates in each year. Following the path of Malaysia's economic development, early debates are dominated by industry and economic development with a greater variety of topics appearing in the debates from the 1980s onwards. After 1979, debates in most years included some mention of environmental protection, conservation and impact topics. Topics related to the category of industry and economic development are consistently discussed. 


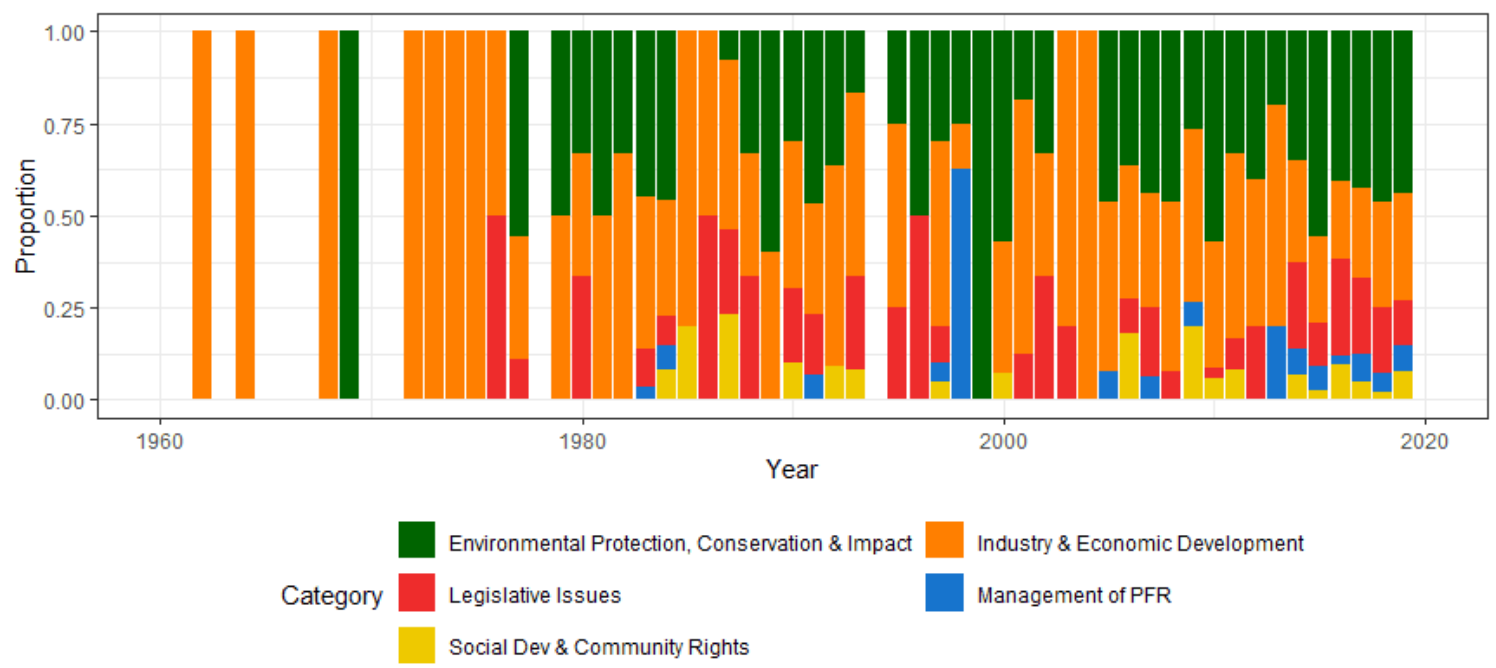

Figure 3. Relative proportion of categories in debates per year (Source: NVivo)

Figure 4 shows that PRF references in the parliamentary debates peaked in several different periods. These correspond to several key events in Malaysia, which have been labelled on the Figure. In order to analyse this further, the topics and themes presented in Figure 1 were divided based on these events; 1] the passage of the National Forestry Act 1984 which formalizes the gazettement of PRF; 2] the 1992 Rio Earth Summit which introduced the concept of sustainable development in Malaysian policies; 3] passage of the Wildlife Conservation Act 2010 and finally, 4] State and Federal government conflict.

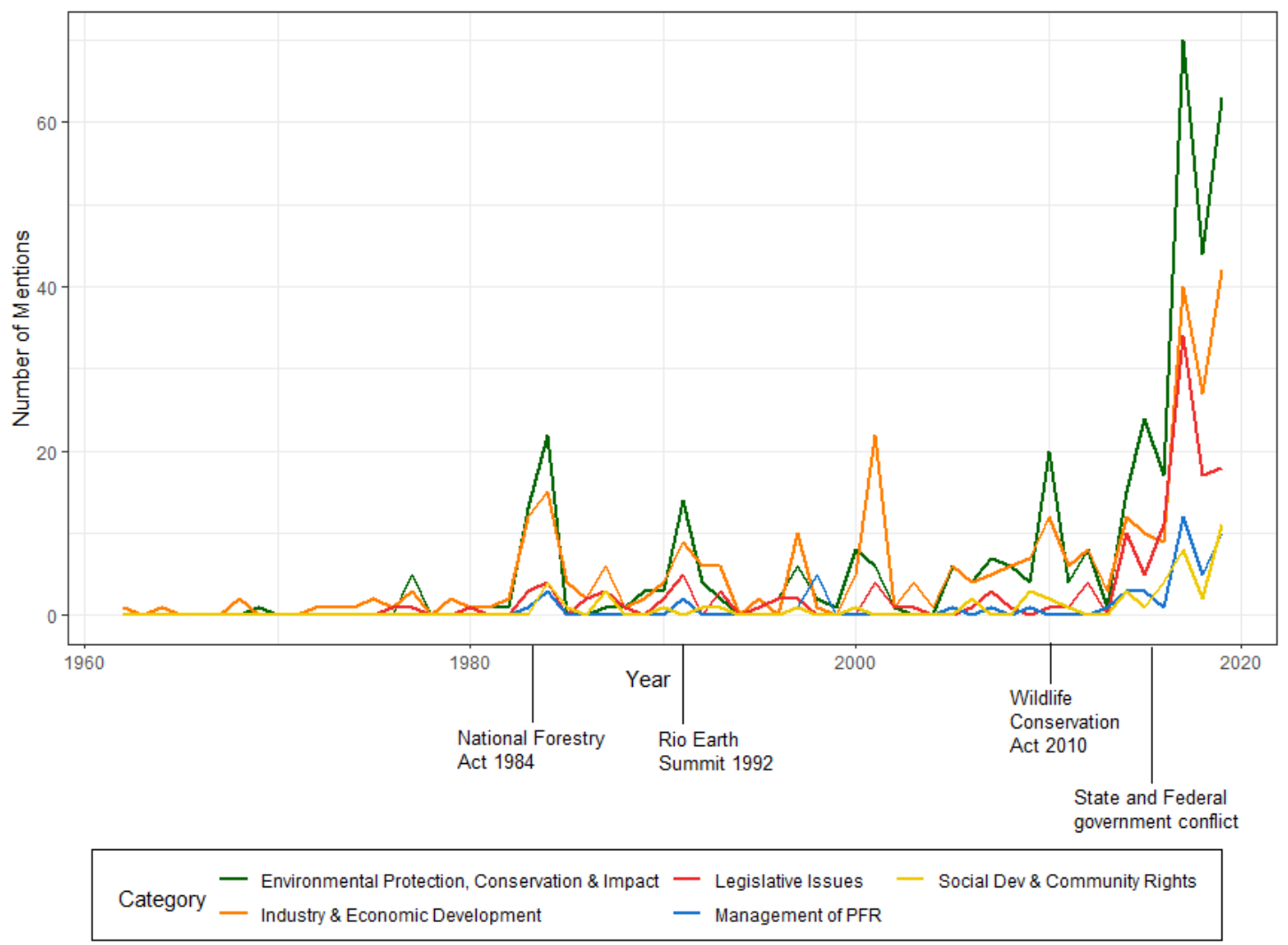

Figure 4. Changes in the frequency of key themes in PRF over time (Source: NVivo) 


\subsection{National Forestry Act 1984}

As a British colony, pre-independence Malaya was a major source of timber, rubber and other natural resources for Britain (Swettenham, 1906), so forestry practices were well established by the time Malaysia emerged as an independent country. Post-independence, official discussions regarding forests revolved predominantly around its economic contribution to the country and society, issues of developing forest land for agriculture, and the improvement of logging methods to maximise timber yield. The concept of PRF had yet to be introduced during this time period, which explains why very few references to forest reserves were found in early debates. However, the term 'forest reserve' or 'hutan simpan' itself had already been used, as stated in Section 1.2. The definition of the term at this period of time was vague and unclear, as evidenced by the debates of the members of Parliament. In fact, in the early years, very few changes were recorded in the discourse on forest reserves. However, in the 1970s, members of parliament started to become concerned with the supply of timber. This is shown in the quote by Datuk Musa Hitam, the Minister of Primary Industries back in 1977,

Translation: I realise that now forest resources in this state [country] are dwindling. My Ministry has refined this matter and believes that to overcome the reduction in timber production and also to avoid this resources from finishing therefore the current forest management has to be improved.

[DR19071977.26]

There was no specific event to mark the change in the parliamentary debates early in this period, however, statistics from the archive of the Department of Statistics showed that the size of forest that was logged for timber had reduced. It is unclear whether this reduction in logged forest is due to the rising concern of forest resource supply or vice versa. Parliamentary debates on PRF during the late 1970s slowly moved towards protecting and conserving forest resources, not necessarily for the protection of the environment, but mainly to prolong the lifespan of the timber industry. Hence, just prior to the introduction of the NFA in 1984, discussions moved towards reforestation needs and silviculture practices.

1984 indicated the first time in which discussion on PRF peaked (Figure 4), mainly due to the fact that this marked the instance in which the concept of PRF was officially recognized within legislation. Not only that, the period between 1984 and early 1990 marked a significant change in the topics discussed in the parliamentary debates on PRF, despite no major changes were made to the ways in which the forests are managed and developed. During the discussion on the legislation, various references were made regarding the need for reforestation and silviculture practices which would ensure a continuous supply of resources such as rattan and timber. Illegal logging was also actively debated not just in PRFs but in forests in general. Throughout, efforts by the Federal government in designating more lands for PRFs were continuously lauded by various members of Parliament. This was seen as a positive step towards ensuring the protection, conservation of forest and also its supplies. Although more and more references were made on the importance of PRFs to not only forest resources but also to the environment, climate balance, water supply and the protection of soil against erosion, the overall tone of the debate revolved around the need for the Act to ensure the uniformity of the governance of the forests to ensure a continuous protection and supply of resources. To quote the MP Megat Junid Megat Ayob, the purpose of the National Forestry Act is to;

'develop the forestry sector systematically for long term benefits'

[DR16101984.33]

However, it is important to note that not only did the discussion on the NFA sparked a more intensive debate on the benefit of PRFs to the environment and wildlife, the members of the parliament (MPs) had also highlighted the vagueness of the legislation in specifying the 
responsibility of licensing and conservation of forest. Furthermore, it was also discussed within the parliamentary debates that the federal-state relationship could provide another barrier in the enactment of legislation due to the differing interest of the state which predisposes towards economic gains. This is vital information that provides evidence of existing flaws within the legislation which had already been highlighted before it was even enacted. Today, not only did the NFA cause significant changes in how forests are now viewed, the Act also provided a guideline on the management of PRF. Therefore, since the issues within the Act were not sufficiently addressed before its enactment, this has contributed to various conflicts related to management, jurisdiction (Azizan et.al, 2017) and participation (Yaakob, 2014), among others, within the PRFs .

By the early 1990s, more MPs had started to take notice of the destruction brought upon the forests in Malaysia and realised that the forest can no longer provide a limitless supply of resources. Indiscriminate logging and development of forests had wiped out vast areas of forests (Miyamoto et.al, 2014), causing untold damage to the environment and economy. However, the underlying tone of the debate regarding PRFs in Malaysia during this time period still centred on economic pursuits and timber.

\subsection{Rio Earth Summit 1992 and Sustainable Development}

Several years after the implementation of the NFA (1984), the MPs still lack understanding on the role of PRFs in Malaysia. Frequently, the Ministry of Primary Industry was called upon to clarify the real purpose of PRFs - which is for sustainable logging management as opposed to for protection - as well as the difference between production and protective forest, as these were misunderstood by some MPs. Early in this period, more and more MPs were starting to question the replacement of PRFs that had been developed by private and governmental agencies, as well the questionable practices of 'sustainable' logging, which, despite assurances from the Ministry of Primary Industries, garnered a significant amount of protests due to the fact that there were visual evidence of the clearing of PRFs. In fact, later in this period, data showed that of the 14.1 million hectare of PRFs gazetted by 1995 , only 3.4 million was classified as protected. This indicated that there were approximately 11 million hectares of PRFs in Malaysia that would eventually be logged. Additionally, a statement by then Deputy Minister of Primary Industries, Dato' Haji Tengku Mahmud bin Tengku Mansor, revealed that despite being classified as protected, even a protected PRF can be logged for timber.

Translation: This PRF can actually be logged... while PRF for water catchment (protection) is actually, for now has no legislation which would prevent it from being logged.

[DR28061991.14]

This statement referred to the status of PRF. Until this point, the government has maintained that a PRF can be either classified as; 1] productive - for timber production-, 2] research and education, 3] recreation or 4] protection. All this is to ensure the continuity of the forest resources as well as protection of biodiversity and water catchment area. However, this statement clearly showed that despite being classified as protected, there is no legislation which could prevent a protected PRF from being logged.

This period also saw a rise in international pressure regarding the questionable logging practices in Malaysia. This was partly associated with the Rio Earth Summit and the rise of the sustainable development concept. Additionally, international NGOs and various 'western' countries also started to take notice of, and protested against, the unsustainable and destructive logging practices carried out in Malaysia. Based on the content of the debates, actions such as producing explanatory documents and inviting NGOs for visits, indicates that Malaysia's response was to 'educate' and inform the 'green' people of what they were mistaken about, rather than to adapt our practices. The general consensus was that Malaysia had been wrongfully accused and, although 
concern regarding the management of PRFs was evident, more emphasis was given to the image Malaysia was presenting to the international community.

In essence, the overall perception of the government towards forests became evident based on the speeches made by the MPs. Although touted as the best possible option to manage forests in Malaysia, PRF and sustainable forest management clearly legitimized large-scale logging under the pretext of selective logging, silviculture and reforestation. Economic attainment was still at the forefront of debate. Furthermore, although the government's pledge of ensuring $50 \%$ of the country is kept covered by forests, and that several MPS had claimed that the pledge had already been fulfilled, what was actually considered as a 'forest' was merely the presence of trees. For example, in a statement by another then Deputy Minister of Primary Resources, Datuk Seri Lim Keng Yaik,

Translation: At least 50\% of our land is kept as forest....... Or forests that have been planted. You mean our farms are not forests?.... (Our trees) with big leaves can that not be counted as forest? Forest farms that we have planted - planted forest! Come on, if it is so, more than 65\%. What is there to be afraid of. Do you want us to make everything into a forest until there is nothing left, no more land..."

[DR04081993.116-117]

This clear indication of forest as merely a group of trees instead of a complex ecosystem reflected the direction of conservation and development in Malaysia over the next decade.

\subsection{Wildlife Conservation Act 2010}

In part due to the increased concern over the exploitation of Malayan Tigers, especially in the months leading to the Chinese New Year celebration in 2010, a new Wildlife Conservation Act 2010 was introduced to replace the outdated Protection of Wildlife Act 1972. Considered to be stricter in wildlife protection and penalties compared to its predecessor, the year leading up to the enactment of the legislation also shows an increase in discussion regarding PRF. Although it was explicitly mentioned within the parliamentary debate that the Act does not involve the protection and conservation of forest and forest reserves, several MPs made it clear that protection of wildlife and the forest ecosystems should go hand in hand.

Initially, discussions in this period, which was around the early 2000s, revolved around the benefit of PRF as a permanent habitat for wildlife, and how the protection of the former would also ensure the protection and conservation of the latter. However, towards the year 2010, discussions on PRF slowly moved away from the protection of wildlife and towards the issues involved with the management of PRF. Although these management issues had already been mentioned, it is clear that the dominant discussion on PRF had now shifted from the protection and conservation of wildlife to conflict and problems in the development and management of PRF in Malaysia.

\subsection{State and Federal Conflict (2010 onwards)}

During this period, the conflict between the state and federal government became more apparent as there were continuous references to the division and jurisdiction of power between the state and federal government. Although this is nothing new in the discussions surrounding the management of PRFs, the occurrences of the topic is more frequent in this period. Discussions became less about the role and management of PRF and more about the legal and ethical aspect of managing and protecting the PRFs. This includes issues with land jurisdiction, enforcement rights, licensing, as well as conflicts between the public and the development of PRF. Unlike previous periods, it is difficult to link specific events or legislation to the rise in discussions regarding government conflict in PRF. However, this period coincides with the increasing political conflict and tension in Malaysia, which is especially high, especially several years prior to the general election in 2013. This election recorded the highest number of Parliament seats claimed by the Opposition, marking the near loss of the Barisan Nasional's (National Front) dominance in Malaysian politics. 
Another issue that can be alluded to the conflict between the state and federal government is the issue of compensation from the federal government to the state for protecting the forests. State government felt that compensation was due to them since protecting the forest reserves resulted in a perceived loss of income. However, the MPs indicated that the federal government felt that being able to protect the environment for the sake of future generations should be a reward in itself. Regardless, the conflict between these two levels of government highlighted the lack of power of the federal government in ensuring the protection of forests. As stated by MP Dato' Lilah Bin Yasin,

Translation: I raised the issue of forest because most of the stuff we discussed in this Parliament in the end The Honorable Minister will answer that it is under the jurisdiction of the state government. Therefore, this issue will continue when some state governments are irresponsible carrying out the destruction of the forest, clearing of the forest, which resulted in the end us not being able to protect the wildlife. (DR 13072010)

\section{Discussion}

Over the course of 60 years, the discussion on PRFs became more complex, involving the debate of a greater range of topics. Some new topics emerged in the early 2000s which considered the diversification of the forestry industry, the potential for tourism and ecotourism as well as the vital need to reduce the reliance on timber. In fact, ecotourism had taken over as the dominant economic discourse with logging no longer seen as a viable economic pursuit. It is viewed as the answer for both economic development and conservation of natural areas, although recent evidence has since indicated that ecotourism may in fact contribute to further deforestation (Brandt \& Buckley, 2018).

In recent years, environmental concerns and the importance of forests to combating climate change have increased in perceived importance on the global scale. From this analysis, it is clear that the same debate is also increasing within the Malaysian Parliament. However, although debates on environmental issues related to PRFs are increasing in Parliament, it is still secondary to the debates on economic development of PRFs. Additionally, the issue of water sources and water pollution were also actively discussed. This is due to the fact that logging and development had caused severe damage to water catchment areas, which caused pollution and disrupted water supply to the people (Camara et al., 2019). There was a peak in the number of discussions on PRF following the Rio Earth Summit and the rise of the concept of sustainable development. Internal concern regarding how PRFs were managed rose in tandem with the pressure put upon Malaysia by international NGOs and other countries. As a result, a greater emphasis on sustainable development was introduced, partly for the practicality of the concept that promotes a sense of 'holistic' development, but mainly to stop further scrutiny from international sources (Kathirithamby-Wells, 2005).

In truth, debates on environmental protection and conservation are still lagging behind, and have since remained a debate in parliament that is yet seen to translate significantly into any working policy. Unfortunately, many environmental policies in Malaysia are based on scientifically inappropriate assumptions (Hezri, 2016). For forestry, policies and plans are based on economics rather than ecology and environmental conservation, hence the conflict. PRFs, for instance, was created to sustainably manage timber, and yet, over the years, the perception of the MPs had changed into the idea that PRF is to protect and conserve the environment and the complex forest ecosystems. However, the documented policy regarding the role of PRF has not changed to reflect this shift in public perception. Somehow along the way, the real purpose of PRF had been forgotten and PRF is now viewed as a measure of protection for forests in Malaysia. Hence, contributing to the growing conflict between the management of PRF for economic resources and environmental protection.

Nevertheless, it is unfair to simply categorise the PRFs and its current sustainable forest management (SFM) as an issue within the management of forests in Malaysia. Imai et al. (2009), for instance, highlight the importance of sustainably managing production forests for biodiversity protection and carbon sequestration in the absence of large areas of pristine forests. Langner et. al, (2012) had also recognised the benefit of SFM over conventional logging, as the former is able to 
maintain its level of above-ground biomass, a term used to indicate vegetation covers. This means that SFM allows these degraded areas to mitigate the worst effects of logging. Regardless, the use of SFM for PRFs in Malaysia should not negate the fact that we are still lacking in policies that aim for forest protection, rather than forest production, no matter how sustainable it is. Chiat Lee and Baharuddin (2018), for instance, highlighted the critical need for laws preventing deforestation in Malaysia in order to alleviate environmental problems such as flooding and climate change.

Another point to highlight in this article is the discussion of the ethical issues in PRF management, as evidenced by the plight of the indigenous people, especially the Penans. The Penans are indigenous groups of people, who were displaced due to the indiscriminate logging and corruption which had taken place in Sarawak (Sahabat Alam Malaysia, 1992; Osman, 2000). This discussion highlighted the lack of public participation pathways in Malaysian legislative system which allows the public to take part in the management, protection and the development of PRF, causing the public to be marginalised. Although the issue of indigenous people and the impact of PRF development on the public had been mentioned sporadically throughout the past 60 years, very little had been discussed on the issue of public participation in the management of PRF, and this was also related to the lack of environmental and procedural justice which does not allow the full participation of the public in PRF decision making process (Azmi, 2019). In fact, The Penans were clearly highlighted as a prime example of the ethical and justice issues in Malaysia, as it symbolises the marginalisation of the public, who stand outside of the decision making structure in the country. As MP Fuziah Salleh eloquently put it,

Translation: This is another issue that we have to question, that we have to understand because if we want to talk about sustainable development, we have to understand this issue. It's legal but is it ethical? What are the moral obligations, with permission, Mr. Speaker, to our children and grandchildren, the next generation'

[DR08062015.36]

This statement, taken from the 2015 debate, is the closing speech given by MP Fuziah Salleh on the lack of ethical considerations in environmental management in Malaysia. She highlighted the poor ranking of the country in the Environmental Democracy index, citing lack of available information, poor public participation, and lack of access to justice, as some of the issues which need to be tackled.

All of these issues highlight the continuous and unresolved conflict that exists within the governance of PRFs. Unfortunately, despite governmental propaganda that promises 50\% forest cover, the fact that most of the forests are categorized as PRFs means that our forests can be continuously and legally - if not ethically - logged or exploited, not to mention that its status as a forest is precarious, as power to excise forest from its PRF status belongs solely with the state government. Not only that, since PRF by definition is for the sustainable production of forest resources, continued gazettement of PRF and the practice of sustainable forest management gives the people the illusion of forest protection. This is concerning, as it affects Malaysians perception on how the forestry sector is governed. Nagulendran et al. (2016), for instance, engaged with a wide range of stakeholders to identify conservation themes and priorities. They found that members of the government had, on average, more positive opinions on the state of protected areas and wildlife in Malaysia compared to members of NGOs, academia and the private sector. However, Nagulendran et al. (2016) also found that policy and management of protected areas and wildlife was seen as inadequate by various stakeholders, citing issues such as lack of leadership, ineffective implementation, and conflicting policies. Not only that, in this situation, the people remain powerless to stop any action taken by the state government, as public participation exists only in name and any action cannot be taken without the cooperation and consent of the state government.

This study strives to provide a comprehensive analysis of discussions on PRFs in parliamentary debates in Malaysia. However, it must be noted that an analysis on parliamentary debates is limited 
to the discussion by the MPs and cannot be generalized to the opinion of the public. Regardless, this research is critical as it both highlights the conflicts within the governance of PRFs but also the lack of progress made towards resolving it.

\section{Conclusions}

In general, the parliamentary debates have been dominated by economic issues. This is somewhat unsurprising considering the government's desire for Malaysia to develop economically and the importance of the forestry sector to the country's economy in the past. It is also important to remember that the original focus of these forest reserves was to sustainably manage timber rather than provide complete protection of forested areas. Nevertheless, the results have shown that environmental issues were considered in debates and its frequency is increasing, especially in light of the change in government (Nadzri, 2018), breaking six decades of control by the former government. This indicates hope that sometime in the future, that a more significant change might occur, however, with both the fall of the new government in just two years (Parameswaran, 2020) as well as the pandemic, which challenged forestry conservation efforts, the fate of Malaysian forests remains to be seen.

All in all, the results of this analysis are discouraging in some ways, such as the limited discussion of ethical considerations throughout the period. Not only that, this analysis has also shown the issues and conflict within our practices and legislation that can continuously challenge efforts to protect our increasingly limited natural resources. However, as more and more people are made aware of the fundamental problems we experience, perhaps a more concrete solution can be achieved. It is important, after all, for the public to understand that PRFs are not for protection, and that the term itself is a misnomer. In this, further research is needed in order to actively challenge the current policies on forest protection and how forests are managed. Not only that, alternatives are needed, to ensure that Malaysia can shift its focus from forests as resources to be exploited to one that should be protected. The question remains, how do we do that, without compromising the economy?

Author Contributions: Alia Azmi conceived and conducted the research as well as wrote the main texts, while Rhosanna Jenkins provided assistance with analysis of data, editing and the final write-up of the article.

Conflicts of Interest: The authors declare no conflict of interest. This article is part of research funded by Universiti Teknologi MARA

Acknowledgments: Special acknowledgement to both Universiti Teknologi MARA for the funding (Young Lecturer Scheme) and Andrew Lovett of University of East Anglia who contributed ideas that helped with the analysis

\section{References}

Azizan, M. U., Bing, T. S., Raid, M. M., Mohammad, M. T. S., Hussin, K., Abd Rahman, M. M. G. M., \& Nadzri, M. I. (2017). Conflicting Role of Land Office and Forestry Department: A Comparative Discussion Regarding to Forest Offences Prevention in Malaysia. Jurnal Ilmu Lingkungan Undip, 15(1), 11-19. https://doi.org/10.14710/jil.15.1.11-19

Azmi, A. (2019). Analysis Of (Un)Invited Participation Using Environmental Justice In Permanent Reserved Forest In Peninsular Malaysia. University of East Anglia, Norwich, UK

Brandt, J. S., \& Buckley, R. C. (2018). A global systematic review of empirical evidence of ecotourism impacts on forests in biodiversity hotspots. Current Opinion in Environmental Sustainability, 32, 112-118. https://doi.org/10.1016/j.cosust.2018.04.004

Camara, M., Jamil, N. R., \& Abdullah, A. F. B. (2019). Impact of land uses on water quality in Malaysia: a review. Ecological Processes, 8(1), 1-10. https://doi.org/10.1186/s13717-019-0164-x

Gatti, R. C., Liang, J., Velichevskaya, A., \& Zhou, M. (2019). Sustainable palm oil may not be so sustainable. Science of the Total Environment, 652, 48-51. https://doi.org/10.1016/j.scitotenv.2018.10.222 
Hardy, C., Harley, B., \& Phillips, N. (2004). Discourse analysis and content analysis: Two solitudes. Qualitative methods, 2(1), 19-22.

Hezri, A. (2016). The Sustainability Shift: Refashioning Malaysia's Future: Areca Books.

Imai, N., Samejima, H., Langner, A., Ong, R. C., Kita, S., Titin, J., ... \& Kitayama, K. (2009). Co-benefits of sustainable forest management in biodiversity conservation and carbon sequestration. PLoS One, 4(12), e8267. https://doi.org/10.1371/journal.pone.0008267

Jusoff, K., \& Taha, D. H. D. H. (2008). Sustainable forest management practices and environmental protection in Malaysia. WSEAS Transactions on Environment and Development, 4(3), 191-199.

Kathirithamby-Wells, J. (2005). Nature and Nation: Forests and Development in Peninsular Malaysia. University of Hawai'i Press.

Kanniah, K. D., Tan, K. P., Cracknell, A. P., Huete, A. R., Idris, N. H., Lau, A. M. S., ... \& Ahmad, A. (2018). Assessment of biophysical properties of Royal Belum tropical forest, Malaysia. Singapore Journal of Tropical Geography, 39(1), 90-106. https://doi.org/10.1111/sjtg.12215

Langner, A., Samejima, H., Ong, R. C., Titin, J., \& Kitayama, K. (2012). Integration of carbon conservation into sustainable forest management using high resolution satellite imagery: A case study in Sabah, Malaysian Borneo. International Journal of Applied Earth Observation and Geoinformation, 18, 305-312. https://doi.org/10.1016/j.jag.2012.02.006

Lee, W. C., \& Baharuddin, A. H. (2018). Impacts of climate change on agriculture in Malaysia. In The Impact of Climate Change on Our Life (pp. 179-195). Springer, Singapore. https://doi.org/10.1007/978-981-10-7748-7_10

Miyamoto, M., Parid, M. M., Aini, Z. N., \& Michinaka, T. (2014). Proximate and underlying causes of forest cover change in Peninsular Malaysia. Forest Policy and Economics, 44, 18-25. https://doi.org/10.1016/j.forpol.2014.05.007

Myers, N. (1988). Threatened Biotas: hot spots in tropical forests, the Environmentalist, 8, 187-208. https://doi.org/10.1007/BF02240252

Nadzri, M. M. (2018). The 14th General Election, the fall of Barisan Nasional, and political development in Malaysia, 1957-2018. Journal of Current Southeast Asian Affairs, 37(3), 139171. https://doi.org/10.1177/186810341803700307

Nagulendran, K., Padfield, R., Aziz, S.A., Amir, A.A., Rahman, A.R.A., Latiff, M.A., Zafir, A., Quilter, A.G., Tan, A., Arifah, S. and Awang, N. (2016). A multi-stakeholder strategy to identify conservation priorities in Peninsular Malaysia. Cogent Environmental Science, 2(1), p.1254078. https://doi.org/10.1080/23311843.2016.1254078

NFA (1984). National Forestry Act 1984, Malaysia, The Commissioner Of Law Revision.

Natural Resources and Environment. (2016). Malaysia: National policy on biological diversity (20162025). Putrajaya: Ministry of Natural Resources and Environment Malaysia (NRE).

Natural Resources and Environment (2017). Forestry Facts. Retrieved from http://www.nre.gov.my/en-my/Forestry/Pages/Forestry-fact.aspx

O'Neill, E., Devitt, C., Lennon, M., Duvall, P., Astori, L., Ford, R. and Hughes, C., (2018). The dynamics of justification in policy reform: insights from water policy debates in Ireland. Environmental Communication, 12(4), 451-461. https://doi.org/10.1080/17524032.2018.1429478

Osman, S. (2000). Globalization and democratization: the response of the indigenous peoples of Sarawak. Third World $\quad$ Quarterly, 21(6), 977-988. https://doi.org/10.1080/01436590020011981

Parameswaran, P. (May, 2020) What Does Malaysia's Troubled Transition Mean for Democracy in South East Asia?. The Diplomat. Retrieved from https://thediplomat.com/2020/05/whatdoes-malaysias-troubled-transition-mean-for-democracy-in-southeast-asia/

Parlimen Malaysia (2020) Senarai Penyata Rasmi (Hansard). Retrieved from https://www.parlimen.gov.my/hansard-dewan-rakyat.html?uweb=dr\&arkib=yes

Ratnasingam, J., loras, F., Neelakandan, G., Mariapan, M., \& Swan, T. T. (2011). Malaysian Forestry: Past, Present and the Future (pp. 138). Retrieved from http://www.forr.upm.edu.my/dokumen/90401_Forestry.pdf 
Riggs, R. A., Langston, J. D., Beauchamp, E., Travers, H., Ken, S., \& Margules, C. (2020). Examining trajectories of change for prosperous forest landscapes in Cambodia. Environmental management, 66(1), 72-90. https://doi.org/10.1007/s00267-020-01290-9

Sahabat Alam Malaysia (1992). Environmental displacement in Malaysia: The Effects of the development process on rural and native communities. Refuge: Canada's Journal on Refugees, 15-19.

Sarrica, M., Brondi, S., Piccolo, C., \& Mazzara, B. M. (2016). Environmental consciousness and sustainable energy policies: Italian parliamentary debates in the years 2009-2012. Society \& Natural Resources, 29(8), 932-947. http://dx.doi.org/10.1080/08941920.2015.1095379

Swettenham, F. A. (1906). British Malaya: An Account of the Origin and Progress of British Influence in Malaya. J. Lane.

Varkkey, H. (February, 2019) Winds of Change in Malaysia: The Government and the Climate. Heinrich Boll Stiftung, Southeast Asia. Retrieved from https://th.boell.org/en/2019/02/27/winds-change-malaysia-government-and-climate

Yaakob, A. (2014). A legal analysis on law and policy on conservation of forest in Peninsular Malaysia/Adzidah Binti Yaakob. Doctoral dissertation, University Malaya.

Zeng, Z., Estes, L., Ziegler, A.D., Chen, A., Searchinger, T., Hua, F., Guan, K., Jintrawet, A. and Wood, E.F. (2018). Highland cropland expansion and forest loss in Southeast Asia in the twenty-first century. Nature Geoscience, 11(8). 556-562. 